\title{
Annual report 2015
}

\author{
Manfred Gerlach $^{1}$
}

Published online: 19 February 2016

(C) Springer-Verlag Wien 2016

During the last few years, ADHD Atten Def Hyp Disord, the official journal of the World Federation of ADHD (WFADHD), has seen a rapid development. Members of the WFADHD can download the journal for free in the members area of the homepage of the WFADHD at www. adhd-federation.org.

The number of submissions from all over the world continues to increase and may reach more than 80 by the end of this year. Some of our articles have reached a large readership. For example, the article The history of attention deficit hyperactivity disorder by Lange et al. (2010) was downloaded more than 2500 times and Stigma in attention deficit hyperactivity disorder by Mueller et al. (2012) more than 1200 times. In 2015, the most popular paper (downloaded 990 times) was Associations of sleep disturbance with ADHD: implications for treatment by Hvolby (2015).

We have received 67 regular articles. Our acceptance rate is about $76 \%$, and it takes an average of 50.4 days from submission to production. Although we are able to publish accepted papers online in a timely manner, we face a backlog of papers that have been published online but not in print.
I am pleased to inform you that ADHD Atten Def Hyp Disord was selected for inclusion in the Emerging Sources Citation Index (ESCI), which is the new database introduced by Thomson Reuters. This means that the 2015 issue will be included in the Web of Science, where the citations will get more exposure due to discoverability and thus a higher chance of getting cited. Based on the citation activity, the journal will be considered for the core collection and possibly obtain an impact factor. This is an important challenge that we are taking up since the founding of ADHD Atten Def Hyp Disord, 6 years ago. If we could obtain an impact factor, the journal would acquire more high-quality submissions.

I am writing to ask for your support. We would be grateful if you would consider submitting high-quality reviews as well encouraging your co-workers and colleagues to submit scientific articles in order to increase the citation activity, thus increasing our chances of obtaining an impact factor.

I would like to thank all our authors and reviewers for their valuable contributions, allowing such an increase in quality.

I look forward to continuing the journal's success.

\section{References}

Hvolby A (2015) Association of sleep disturbance with ADHD: implications for treatment. ADHD Atten Def Hyp Disord 7:1-18

Manfred Gerlach

manfred.gerlach@uni-wuerzburg.de

1 Center for Mental Health, Clinic for Child and Adolescent Psychiatry, Psychosomatics and Psychotherapy, University Hospital Würzburg, Füchsleinstrasse 15, 97080 Würzburg, Germany
Lange KW, Reichl S, Lange KM, Tucha L, Tucha O (2010) The history of attention deficit hyperactivity disorder. ADHD Atten Def Hyp Disord 2:241-255

Mueller AK, Fuermaier ABM, Koerts J, Tucha L (2012) Stigma in attention deficit hyperactivity disorder. ADHD Atten Def Hyp Disord 4:101-114 